\title{
SOBRE EL «NEOINDIGENISMO» Y LAS NOVELAS DE MANUEL SCORZA
}

POR

ANTONIO CORNEJO POLAR

Universidad Nacional Mayor de San Marcos, Lima, Perú

En su tesis doctoral sobre la narrativa indigenista peruana, Tomás G. Escajadillo propuso periodizar en tres tramos el proceso de ese movimiento: indianismo, indigenismo ortodoxo y neoindigenismo. Actuante a partir de la década de los cincuenta, o en todo caso después de la fecha en que aparecen las novelas que culminan y en cierto modo agotan la capacidad creativa del indigenismo ortodoxo (El mundo es ancho y ajeno y Yawar fiesta, ambas de 1941), el neoindigenismo se definiría por la convergencia de los siguientes caracteres:

a) El empleo de la perspectiva del realismo mágico, que permite revelar las dimensiones míticas del universo indígena sin aislarlas de la realidad, con lo que obtiene imágenes más profundas y certeras de ese universo.

b) La intensificación del lirismo como categoría integrada al relato.

c) La ampliación, complejización y perfeccionamiento del arsenal técnico de la narrativa mediante un proceso de experimentación que sur pera los logros alcanzados en este aspecto por el indigenismo ortodoxo.

d) El crecimiento del espacio de la representación narrativa en consonancia con las transformaciones reales de la problemática indígena, cada vez menos independiente de lo que sucede a la sociedad nacional como conjunto.

Esta última característica, pero no sólo ella, hace necesario debatir si el neoindigenismo es una transformación orgánica de la tradición anterior o, más bien, su cancelación. Escajadillo opta por lo primero, pero establece como campo propio del neoindigenismo una delgada franja en la que solamente aparecen insertos los relatos del «segundo Arguedas», el de Los ríos profundos y «La agonía de Rasu Niti», todos los cuentos. 
de Eleodoro Vargas Vicuña y algunos de Carlos Eduardo Zavaleta ${ }^{1}$. Los dos últimos pertenecen a la llamada «generación del 50».

La caracterización que propone Escajadillo es correcta; sin embargo, sería necesario articularla con una concepción general del indigenismo que no se limitara a definirlo por su referente (el mundo indígena) y por su intencionalidad (una literatura de denuncia y reivindicación), sino que pudiera observar prioritariamente su proceso de producción. Esta perspectiva permite ver lo que es esencial en el indigenismo: su heterogeneidad conflictiva, que es el resultado inevitable de una operación literaria que pone en relación asimétrica dos universos socioculturales distintos y opuestos, uno de los cuales es el indígena (al que corresponde la instancia referencial), mientras que el otro (del que dependen las instancias productivas, textuales y de recepción) está situado en el sector más moderno y occidentalizado de la sociedad peruana. Esta contradicción interna reproduce la contradicción básica de los países andinos ${ }^{2}$.

Las tensiones transculturales y pluriclasistas del indigenismo decrecen, o se formulan de manera menos drástica, en la década de los cincuenta. Por lo pronto, en el plano de la realidad, se evidencia por entonces una creciente intercomunicación, aunque por cierto no igualitaria, entre los distintos segmentos de la sociedad peruana, en especial a través de las migraciones andinas hacia la costa y de la expansión de los patrones culturales citadinos sobre los ámbitos rurales. Naturalmente, estos hechos no significan la integración del país, pero sí implican el acortamiento de la distancia que separaba al sistema sociocultural indígena de la sociedad y la cultura que producía (y produce) el discurso indigenista. Es igualmente claro que esta nueva situación no resuelve la heterogeneidad del indigenismo; por consiguiente, los narradores indigenistas de la «generación del $50 »$, los neoindigenistas, tienen que enfrentarse al mismo problema que agobiaba a sus antecesores: ¿cómo revelar el mundo indígena (aunque ahora lo indígena aparezca fuertemente mestizado) con los atributos de otra cultura y desde una inserción social distinta? ${ }^{3}$

Los neoindigenistas participan con la casi totalidad de los narradores del 50 en un vasto proyecto de modernización de la literatura peruana,

1 Tomás G. Escajadillo, La narrativa indigenista: un planteamiento y ocho incisiones (Lima: Universidad Nacional Mayor de San Marcos, 1971) [mimeo.].

${ }^{2}$ Cf. mis artículos «Para una interpretación de la novela indigenista» (en Casa, XVI, 100, La Habana, enero-febrero 1977) y «El indigenismo y las literaturas heterogéneas: su doble estatuto sociocultural» (en Revista de Critica Literaria Latinoamericana, IV, 7-8, Lima, 1978).

${ }^{3}$ Cf. Angel Rama, Transculturación narrativa en América Latina (México: Siglo XXI, 1982). 
incluyendo la transformación del escritor en profesional. Curiosamente, la profesionalización del narrador estaba en contradicción práctica con otros aspectos del mismo proyecto, en especial con la voluntad de emplear intensamente las técnicas del relato joyceano y posjoyceano, puesto que, como es obvio, para ese tipo de escritura no existía un público que pudiera solventar la actividad profesional de los escritores. A la larga, los pocos narradores de la "generación del 50» que mantienen una producción más o menos constante tendrán que resignarse a ser «escritores a tiempo incompleto" ${ }^{4}$; esto es, a dejar de lado su ideal de profesionalización. Sobra aclarar que el fracaso de esta parte del proyecto modernizador sólo representa el punto menos dudoso de un fracaso harto más profundo y global. En este orden de cosas, no es en modo alguno casual que del nutrido grupo de narradores que comienza a publicar en la década de los cincuenta, apenas dos, Ribeyro y Zavaleta, persistan sistemáticamente, veinte años más tarde, en esa actividad ${ }^{5}$.

En los cincuenta, Manuel Scorza (Lima, 1928) era conocido y apreciado como poeta. En ese período había publicado dos poemarios importantes: Las imprecaciones (1954) y Los adioses (1958), ambos dentro de la línea de la "poesía social», e intervenido muy activamente en la polémica entre los «poetas comprometidos» y los «poetas puros» ${ }^{6}$. A partir de 1958, sin dejar de desarrollar su propia obra, Scorza se dedica intensamente a promover empresas editoriales (Festivales de Libro, Populibros) destinadas a ampliar de manera sustancial la audiencia literaria en el Perú (y más tarde en otros países hispanoamericanos). Evidentemente, este trabajo tiene que entenderse como el aporte personal de Scorza a una tarea que respondía a las urgencias de toda su generación: crear una industria editorial moderna (implanta el offset para ediciones literarias) y convocar a un público lector masivo; vale decir: fundar las bases para esa nueva literatura escrita por profesionales. El carácter generacional de Populibros se aprecia, además, en sus catálogos. Allí aparecen, a veces por primera vez, la mayoría de los narradores del 50: Ribeyro, Salazar Bondy, Vargas Vicuña, Congrains, Loayza, Reynoso, etc.

El éxito de Festivales y Populibros fue extraordinario, pero fugaz: en pocos años no eran más que el recuerdo de un esfuerzo más voluntarioso

${ }^{4}$ La frase es de Carlos E. Zavaleta y aparece en la encuesta que precede a la antología preparada por Abelardo Oquendo, La narrativa peruana: 1950-1970 (Madrid: Alianza Editorial, 1973), p. 15.

${ }^{5}$ Cf. Antonio Cornejo Polar, "Hipótesis sobre la narrativa peruana última», en Hueso humero, 3, octubre-diciembre 1979.

' Cf. Varios, Narración y poesía en el Perú (Lima: Hueso húmero editores, 1982). 
que orgánico por superar el arcaísmo de la base material de la producción literaria en el Perú. Por lo demás, el hecho de que un poeta tuviera que asumir una actividad empresarial parece indicar no sólo la angustia de los escritores jóvenes que necesitan romper los esquemas de una vida literaria pobre y primitiva, sino también, paradójicamente, las limitaciones y contradicciones del proyecto modernizador: nada menos moderno, en efecto, que el poeta que debe cubrir con su propia actividad las carencias del sistema editorial ${ }^{\text {? }}$.

Como queda dicho, la «generación del 50» recesó muy pronto su producción narrativa. Por esto, cuando en 1964 La ciudad y los perros triunfa internacionalmente y conmueve a fondo la vida literaria peruana, se produce una especie de desconcierto: el éxito de la modernidad señalaba a un novelista más joven, que había mantenido una cierta relación discipular con algunos de los escritores del 50, en especial con Sebastián Salazar Bondy ${ }^{8}$, y se producía por un camino imprevisto diez años antes, el de la internacionalización de la literatura. De alguna manera, el triunfo de Vargas Llosa cierra el esfuerzo destinado a desarrollar una literatura nacional a partir de la fundación de un sistema editorial propio, al mismo tiempo que señala la efectividad de la propuesta internacionalizadora. Más todavía: la primera ola de la nueva narrativa hispanoamericana demuestra que los incumplidos ideales de la «generación del 50» eran, en el fondo, extraordinariamente modestos.

No es el momento de analizar las repercusiones de la nueva narrativa hispanoamericana en la literatura del Perú, pero sí cabe anotar que afectaron sobre todo a los escritores posteriores a los del 50, aunque ninguno de ellos pudo repetir el itinerario de Vargas Llosa. De los narradores del 50, algunos continuaron imperturbablemente su producción literaria, casi como si nada hubiera ocurrido, según se aprecia en el caso de Ribeyro; otros, como Thorne, retornaron a la actividad literaria después de largos años de silencio para adecuarse, con desigual fortuna, a los nuevos códigos del relato; los más continuaron o iniciaron, después de esa experiencia, su alejamiento de la literatura, tal vez abrumados por la magnitud del reto que significaba para el escritor la sola presencia de La ciudad y los perros, La muerte de Artemio Cruz, Rayuela o Cien años de soledad.

Manuel Scorza es un caso aparte. Sin duda deslumbrado por la nueva narrativa hispanoamericana, decide ingresar tardíamente al campo del re-

${ }^{7}$ Una tarea similar realizó por esos mismos años un narrador: Alberto Bonilla.

${ }^{8}$ Cf. Mario Vargas Llosa, "Sebastián Salazar Bondy y la vocación del escritor en el Perú», que aparece como prólogo de Comedias y juguetes (Lima: Moncloa, 1967), que es el tomo I de la incompleta edición de las Obras de Sebastián Salazar Bondy. 
lato, hacerlo por el circuito internacional y no con una novela, sino con cinco, articuladas dentro de un gran ciclo orgánico ${ }^{9}$. Sería tergiversador no añadir que la materia histórica que revela la obra narrativa de Scorza concluye hacia 1962, y que en este caso no es posible desligar la índole del estímulo real, el levantamiento campesino en los Andes centrales del Perú del tipo de escritura escogido para relatar esos hechos. En otras palabras: la opción de Scorza por la narración tiene razones referidas al desarrollo de la narrativa hispanoamericana, pero también se explica por el carácter de los hechos sociales que son materia del relato. Tampoco puede omitirse la condición de testigo, y en cierta medida actor, que tiene Scorza con respecto a la realidad que revela en sus libros ${ }^{10}$.

Redoble por Rancas y las cuatro otras novelas sucesivas relatan, como se ha dicho, el levantamiento campesino que sacudió la sierra central a fines de la década del 50 y durante los primeros años del 60, aunque obviamente sus orígenes son muy anteriores ${ }^{11}$. En este sentido, las cinco novelas de Scorza se inscriben de lleno en una tradición narrativa que se define precisamente por referir esos acontecimientos sociales, que podría denominarse «la novela de la rebelión campesina» y que tiene un antecedente valioso en El amauta Atusparia (1929) de Reyna y dos manifestaciones espléndidas en El mundo es ancho y ajeno (1941) y Todas las sangres (1964). Naturalmente, esta tradición está incorporada, aunque manteniendo una cierta especificidad, dentro del gran curso de la narrativa indigenista.

El ciclo narrativo de Manuel Scorza se instala, pues, en un espacio literario doble: de una parte, está obviamente condicionado por la nueva narrativa hispanoamericana; de otra, se refiere a una tradición anterior, en gran parte discutida y negada por el boom, como es la novela indigenista y más específicamente la novela indigenista de intensa motivación social. Hay que recordar que Todas las sangres fue recibida muy fríamente por la crítica auspiciadora de la nueva narrativa, incluso por quienes habían aplaudido unos años antes Los ríos profundos ${ }^{12}$. Ciertamente,

${ }^{9}$ Tardíamente denominado La guerra silenciosa, el ciclo comprende: Redoble por Rancas (Barcelona: Planeta, 1971), Historia de Garabombo, el invisible (Barcelona: Planeta, 1972), El jinete insomne, Cantar de Agapito Robles (ambas: Caracas: Monte Avila, 1977) y La tumba del relámpago (México: Siglo XXI, 1979).

${ }^{10}$ En el prólogo a Redoble (op. cit., p. 10) señala: «Más que un novelista, e1 autor es un testigo.» En la última novela aparece como personaje. 1977).

${ }^{11}$ Cf. Wilfredo Kapsoli, Los movimientos campesinos en el Perú (Lima: Delva,

${ }_{12}$ Por ejemplo: «Todas las sangres fue una gran decepción», según señala Luis Harss en Los nuestros (Buenos Aires: Sudamericana, 1966), p. 302. 
el cruce de esta doble inserción podría solucionarse acudiendo a la denominación «neoindigenismo», pero sería inútil este recurso nominativo si no se analizara lo que significa en concreto, en las novelas de Scorza, esta versión última del indigenismo.

Por lo pronto, el ciclo narrativo de Scorza comparte con otros textos neoindigenistas la voluntad de ampliar el universo de la representación novelesca o, lo que es lo mismo, la intención de romper la visión insular de la vida indígena como si no tuviera relaciones más o menos orgánicas con el resto de la sociedad nacional. En la obra de Scorza esta ampliación comienza a partir de un hecho real: las luchas de las comunidades del centro es contra los gamonales (como en El mundo es ancho y ajeno), pero también, y sobre todo, contra la Cerro de Pasco Corporation (que no es una institución inventada como «el Consorcio» de Todas las sangres). La evidencia de que la Cerro estaba situada en la década del 60 en el vértice del poder social y económico del Perú, e indirectamente en el foco del poder político, determina que la rebelión de los comuneros de Yanahuanca, Yanacocha y otras comunidades del centro sea un acontecimiento nacional con repercusiones harto más graves que las que pudieran haber tenido los enfrentamientos regionales entre campesinos y terratenientes. De otra parte, el no menos obvio carácter imperialista de la Cerro de Pasco señala que el acontecimiento narrado por Scorza se relaciona con la dinámica de los conflictos entre el imperialismo y los pueblos del Tercer Mundo. Como ya lo había hecho Arguedas en Todas las sangres, Scorza universaliza la problemática del pueblo indígena y de sus esfuerzos liberadores.

Pero la ampliación de la representación novelesca tiene otra - $-\mathrm{y}$ más sutil- dimensión en el ciclo de Scorza. En la última novela, La tumba del relámpago, aparecen en roles protagónicos algunos personajes del mundo urbano moderno del Perú (entre ellos el propio Scorza) e instituciones también representativas de este sector de la nacionalidad (como los partidos políticos, las confederaciones de trabajadores, etc.). Y lo que es más significativo: son estas instancias las encargadas de interpretar lo sucedido en los Andes centrales, de señalar los aciertos y los errores del movimiento campesino (y autocríticamente las deficiencias de su propia actividad), de proponer esquemas de acción político-social para el futuro y de imaginar, por esta vía, el triunfo final de los oprimidos. Algo de esto estaba presente ya en El mundo es ancho y ajeno y en Todas las sangres, sólo que en ambas novelas el impacto de la sociedad moderna en el ámbito indígena está a cargo de personajes campesinos, en mayor o menor medida transculturados por experiencias citadinas, que regresan a sus comunidades para incentivar la rebelión. 
Benito Castro y Demetrio Rendón Willka tienen este significado. Uno y otro deben enfrentarse al arcaísmo de sus comunidades, aunque el segundo sea mucho menos incisivo que el primero en lo que toca al cuestionamiento de ciertas costumbres y valores tradicionales, y ambos proponen una suerte de estrategia para la liberación del campesinado indígena. En el marco de ese enfrentamiento tiene un peso muy especial el debate sobre la función del mito en la vida social indígena y sobre todo en relación con las posibilidades de un levantamiento campesino triunfante. En el ciclo narrativo de Scorza se vuelve a tratar prioritariamente esta problemática, que en el fondo es una variante del tema de la tradición y la modernidad; pero la solución que propone es distinta a las ensayadas por Alegría y Arguedas (que entre sí son, asimismo, diferentes y hasta contradictorias) ${ }^{13}$. A grandes rasgos, la propuesta que Scorza afirma en la culminación del ciclo, en La tumba del relámpago, supone la dolorosa negación de la capacidad movilizadora del mito y la convicción de que la revolución necesita el soporte de una racionalidad moderna y pragmática.

Naturalmente, esta conclusión no deja nunca de ser conflictiva y el proceso de su elucidación tiñe de auténtico dramatismo el significado íntegro de las cinco novelas, aunque de manera más evidente de la última. El narrador no puede ni quiere ocultar su admiración por la racionalidad mítica de los indígenas, representada por los espléndidos pero también atroces tejidos de la vieja Añada, y tiene que reconocer que con los atributos de esa racionalidad se forja la identidad del pueblo quechua y se rechaza el designio aculturador del imperialismo y de la burguesía nacional; al mismo tiempo, sin embargo, le es imposible no percibir que con esos atributos el pueblo indígena no podrá pasar de una situación de resistencia, diseñada fundamentalmente en términos de cultura, a otra de emergencia liberadora, obviamente definida en términos político-sociales. El desgarramiento que implica la conclusión del ciclo de Scorza es aún mayor porque buena parte de la adhesión al campesinado indígena se explica por la admiración que causa su cultura y por la necesidad de preservarla contra el poder homogeneizador de la cultura dominante, lo que contradice más o menos directamente el sentido que se asigna en las novelas al movimiento revolucionario campesino. Después de todo, la revo-

${ }^{13}$ Sobre historia y mito en la novela indigenista, cf. mi artículo «La novela indigenista: una desgarrada conciencia de la historia» (en Lexis, IV, 1, Lima, julio 1980). Sobre el tema en Scorza: Mabel Moraña, «Función ideológica de la fantasía en las novelas de Manuel Scorza» (en Revista de Crítica Literaria Latinoamericana, IX, 17, Lima, primer semestre de 1983), y la reseña publicada en el mismo número de esa revista por Jesús Díaz Caballero sobre La tumba del relámpago. 
lución también implica una transformación de esa cultura cuya integridad se defiende.

La contradicción no es resuelta en las cinco novelas de Scorza, pero en la última se le enfrenta con mayor decisión. En La tumba del relámpago, en efecto, se insiste una y otra vez en la necesidad de elaborar una táctica y una estrategia revolucionarias que acaben con las limitaciones que, en estos órdenes, tiene el pensamiento mítico; pero, con igual insistencia, se señala la urgencia de recomponer los recursos ideológicos de raíz occidental para adecuarlos a los requerimientos específicos de las luchas andinas. Naturalmente, la distancia entre aquella ideología y estos requerimientos es enorme (un personaje advierte que «la desgracia de nuestras luchas es que no coinciden con nuestras ideologías; la rabia, el coraje, son de aquí, y las ideas son de allá», La tumba..., p. 235), pero el proyecto de superar este abismo mediante la reelaboración nacional (o mejor, campesina e indígena) del pensamiento revolucionario aparece como la única solución. El contenido crítico de esta postulación, que afecta sobre todo a los partidos de izquierda, que repiten y no crean una ideología, hace recordar algunos aspectos tempranamente tratados por Arguedas en Yawar fiesta y reiterados, más de veinte años después, en Todas las sangres.

Todo lo anterior indica que en La guerra silenciosa subyace una cierta ambiguiedad en lo que toca a la racionalidad mítica indígena, que tanto es recusada cuanto reivindicada como base que hay que respetar para la reformulación ideológica que se postula, pues de otra manera volvería a desarticularse el pensamiento revolucionario y las condiciones concretas de las rebeliones indígenas, pero esa ambigüedad no queda en el nivel del enunciado narrativo: deja su marca, muy visiblemente, en la construcción de cada una de las novelas del ciclo. En todas ellas, en efecto, Scorza asume vigorosamente la racionalidad mítica y buena parte de sus relatos no pueden entenderse más que a partir de esa opción: no en vano, para poner dos ejemplos obvios, un personaje es invisible y otro puede hablar con los caballos. Por consiguiente, en las cinco novelas el narrador se presenta como portador de los mitos y leyendas que impregnan la cotidianeidad de sus personajes indígenas, frente a los cuales no muestra ningún signo de escepticismo, sino más bien de aceptación entusiasta y acrítica, actitud que sólo cambia al final cuando se comprueba que con esos instrumentos no se podrá ganar la guerra contra la Cerro de Pasco.

A este respecto es indispensable hacer algunas precisiones. En primer lugar, el universo de creencias míticas que despliega el ciclo de Scorza no representa la expresión de contenidos míticos efectivamente vividos por el pueblo quechua del centro, salvo en el caso de las referencias al 
mito de Inkarri, sino de construcciones libres elaboradas por el narrador a partir de la dinámica general de ese tipo de racionalidad, lo que implica que la intencionalidad básica no es la de testimoniar las plasmaciones históricas de esa mítica, sino la de internalizar su estructura mental y hacerla discurrir inventivamente por nuevos cauces. De todas maneras, estos mitos ficticios no armonizan con el carácter realista, y hasta testimonial, de los otros sectores del relato. Y nuevamente salta a la vista la doble inserción de La guerra silenciosa en lo que toca a sus ancestros literarios: de una parte, el realismo mágico; de otra, la novela social.

Parece claro que el empleo de este doble código no resuelve la heterogeneidad propia del indigenismo; al revés, en cierto sentido al menos, la hace más compleja y conflictiva. En efecto, si el indigenismo ortodoxo ponía en tensión la índole del referente con respecto a la normatividad de la novela social, el neoindigenismo de Scorza añade una nueva tensión mediante el empleo de los recursos del realismo mágico que representan, tal como los utiliza el narrador, la modernización del relato y un nuevo alejamiento de su referente. Ciertamente, éste, en la realidad, se ha modernizado, pero de ninguna manera en la magnitud implícita en la renovación de una narrativa que funciona dentro del marco de una intensa internacionalización, como es el caso de la nueva narrativa hispanoamericana. Por lo demás, puesto el problema en otros términos, es obvio que la disgregación sociocultural del mundo andino no ha desaparecido, aunque de hecho se ha reformulado en los últimos decenios, y que, por consiguiente, la literatura que trata de revelar ese carácter sigue conservando su razón de ser. La guerra silenciosa representa, en este orden de cosas, el esfuerzo orgánico más consistente para problematizar la historia reciente de esa quiebra que todavía define a las naciones andinas.

En este sentido, el ciclo de Scorza reproduce, dentro de una tradición que comienza con las viejas crónicas de América, la constitución actual de la heterogeneidad andina. En otras palabras: si se inserta en la modernidad más puntual y se refiere al arcaísmo de la sociedad indígena, es porque esa modernidad y ese arcaísmo siguen coexistiendo, contradictoriamente, dentro de un mismo espacio nacional. No es poco mérito de $L a$ guerra silenciosa haber puesto el problema sobre el eje de la contemporaneidad. 
